\title{
sert
}

\section{DO OBJETO REAL AO MUSEU IMAGINÁRIO: A DOCÊNCIA NO ENSINO SUPERIOR DURANTE A PANDEMIA DO COVID-19}

\author{
DOI: https://doi.org/10.33871/23580437.2021.8.2.105-116
}

\author{
Ana Paula Peters ${ }^{1}$ \\ Luana Caroline Damião ${ }^{2}$ \\ Vivian Letícia Busnardo Marques ${ }^{3}$
}

Resumo: O presente artigo trata das possibilidades do ensino remoto emergencial devido à pandemia do COVID-19 para o curso de Bacharelado em Museologia da UNESPAR - Campus de Curitiba I/EMBAP. Através da possibilidade de integração virtual neste momento pandêmico, gerou-se um trabalho transdisciplinar entre as professoras das disciplinas de "Museu, Patrimônio, História e Memória", "Documentação Museológica I" e "Administração Cultural e Marketing", com o projeto e criação do módulo de ensino intitulado "Do objeto real ao museu imaginário", ministrada para o segundo ano do curso de Bacharelado em Museologia. A problemática do presente projeto foi desenvolver uma aprendizagem significativa propondo que cada estudante buscasse um objeto expressivo em sua própria casa, onde encontrava-se em isolamento, para que o módulo se torne atraente e investigativo para o ensino remoto e aos temas essenciais de cada uma das disciplinas que compunham este trabalho. Os objetivos principais do módulo foram construir uma trajetória de ensino em volta do objeto, desde a análise e desenvolvimento da sua documentação museológica, suas características patrimoniais e referenciais da memória, finalizando com a sua difusão. A atividade

\footnotetext{
${ }^{1}$ Doutora em História e Mestre em Sociologia pela Universidade Federal do Paraná (UFPR). Especialista em História da Arte/Música pela Escola de Música e Belas Artes do Paraná (EMBAP). Licenciada em História pela Universidade Federal do Paraná (UFPR). Licenciada em Música pela Escola de Música e Belas Artes do Paraná (EMBAP). É docente efetiva na Universidade Estadual do Paraná (UNESPAR) no curso de Bacharelado em Museologia, atuando com pesquisas sobre memória e patrimônio, acervos sonoros e audiovisuais, música popular brasileira. E-mail: anapaula.peters@unespar.edu.br Lattes: http://lattes.cnpq.br/9480212256567229 Ordcid: https://orcid.org/0000-00024530-3000

${ }^{2}$ Mestre em Comunicação pelo Programa de Pós-graduação em Comunicação e Temporalidades da Universidade Federal de Ouro Preto (PPGCOM - UFOP). Bacharel em Museologia pela Universidade Federal de Ouro Preto. Possui produções em educação patrimonial e com ações de expografia. Atua com pesquisas referentes à Museologia, Teoria Ator-Rede, Arte Contemporânea, Artes Visuais e Audiovisual. Atualmente é professora colaboradora na Universidade Estadual do Paraná (UNESPAR) no curso de Bacharelado em Museologia, onde também coordena os estágios não obrigatórios do curso. E-mail: luanacarolinedamiao@gmail.com Lattes:http://lattes.cnpq.br/0303778624940890 Orcid: https://orcid.org/0000-0001-7233-3902

${ }^{3}$ Doutoranda em Patrimônio Cultural e Sociedade na Universidade de Joinville (UNIVILLE). Mestre em Comunicação e Linguagens na Universidade Tuiuti do Paraná (UTP). Especialista em História da Arte do Séc. XX. Escola de Música e Belas Artes (EMBAP). Especialista em Conservação de obras sobre papel na Universidade Federal do Paraná (UFPR). Licenciada em Desenho na Escola de Música e Belas Artes do Paraná (EMBAP). Atualmente é docente efetiva da UNESPAR - Campus de Curitiba I - Embap, no curso de Bacharelado em Museologia e Licenciatura em Artes Visuais. Atua com pesquisas na área de conservação e comunicação de acervos. E-mail: vivian.busnardo@unespar.edu.br Lattes: http://lattes.cnpq.br/8203413908672377 Orcid: https://orcid.org/0000-0002-1529-8562
} 
avaliativa dessa proposta foi apresentada nos encontros finais do módulo, quando esta metodologia foi aplicada na constituição de um museu imaginário.

Palavras-chave: objeto; museu; Pandemia COVID-19; ensino superior.

\title{
FROM THE REAL OBJECT TO THE IMAGINARY MUSEUM: TEACHING IN COLLEGE EDUCATION DURING THE COVID-19 PANDEMIC
}

\begin{abstract}
This article deals with the possibilities of emergency remote education due to the COVID19 pandemic for the Bachelor's Degree in Museology at UNESPAR - Campus de Curitiba I/EMBAP. Through the possibility of virtual integration in this pandemic moment, a transdisciplinary work was created among teachers in the disciplines of "Museum, Heritage, History and Memory", "Museological Documentation I" and "Cultural Administration and Marketing", with the project and creation of the teaching module entitled "From the real object to the imaginary museum", given for the second year of the Bachelor of Museology course. The problem of this project was to develop a meaningful learning proposing that each student search for an expressive object in his own home, where he was in isolation, so that the module becomes attractive and investigative for remote teaching and the essential themes of each one of the disciplines that made up this module. The main objectives of the module were to build a teaching trajectory around the object, from the analysis and development of its museological documentation, its patrimonial characteristics and references of memory, ending with its diffusion. The evaluative activity of this proposal was presented at the final meetings of the module, when this methodology was applied in the constitution of an imaginary museum.
\end{abstract}

Key-words: object; museum; pandemic COVID-19; college education.

\section{DEL OBJETO REAL AL MUSEO IMAGINARIO: EDUCACIÓN SUPERIOR DURANTE LA PANDEMIA DEL COVID-19}

Resumen: Este artículo trata sobre las posibilidades de la educación remota de emergencia por la pandemia del COVID-19 para la Licenciatura en Museología de la UNESPAR - Campus de Curitiba I/EMBAP. Mediante la posibilidad de integración virtual en este momento pandémico, se generó un trabajo transdisciplinario entre docentes en las disciplinas de "Museo, Patrimonio, Historia y Memoria", "Documentación Museológica I" y "Administración y Marketing Cultural", con el proyecto y la creación. del módulo didáctico titulado "Del objeto real al museo imaginario", impartido en el segundo año de la carrera de Licenciatura en Museología. El problema de este proyecto fue desarrollar un aprendizaje significativo proponiendo que cada alumno busque un objeto expresivo en su propia casa, donde se encontraba en aislamiento, para que el módulo se torne atractivo e investigador para la enseñanza a distancia y los temas esenciales de cada una de las disciplinas que componen este módulo. Los principales objetivos del módulo fueron construir una trayectoria docente en torno al objeto, a partir del análisis y desarrollo de su documentación museológica, sus características patrimoniales y referentes de la memoria, finalizando con su difusión. La actividad evaluativa de esta propuesta fue presentada en las reuniones finales del módulo, cuando se aplicó esta metodología en la constitución de un museo imaginario.

Palabras clave: objeto; museo; Pandemia del COVID-19; enseñanza superior. 


\section{INTRODUÇÃO}

A criação do módulo "Do objeto real ao museu imaginário" ocorreu com o início do ensino emergencial para o desenvolvimento de atividades remotas no ensino superior, especificamente no curso de Bacharelado em Museologia da UNESPAR - Campus de Curitiba I/EMBAP. O título do módulo foi pensado levando em consideração a palavra "imaginário" no sentido de inexistente, já que os objetos escolhidos fariam parte de um museu que fisicamente não existe, ou seja, seria imaginado pelos discentes a partir dos objetos encontrados na casa de cada um, para a realização das atividades propostas por este módulo ${ }^{4}$. As dificuldades apresentadas pela pandemia relacionadas ao ensino fizeram com que professores e alunos tivessem que se adaptar de forma emergencial: trabalhando em casa com as tecnologias disponíveis à mão, como computadores, celulares e tablets. Estes equipamentos, passam a adquirir novos significados na dinâmica universitária, bem como as ferramentas que poderiam ser utilizadas como intermediárias nesse processo para arquivar e difundir os conteúdos produzidos.

As escolas e as universidades passaram a discutir possíveis adaptações nas metodologias de ensino, para dar continuidade ao processo de ensino-aprendizagem. Foram promovidas diversas discussões conceituais e metodológicas sobre as diferenças e limites com relação à Educação a Distância (EaD), buscando definições sobre um provável e possível Ensino Remoto Emergencial (ERE). Tal cenário está ancorado em legislação federal, o que permitiu algumas adaptações no ensino ao momento em que começamos a viver a partir de março de 2020.

O Decreto n. 9.057, de 25 de maio de 2017, com base na Lei de Diretrizes e Bases da Educação Nacional, vai definir os princípios, os critérios e as diretrizes para a EaD no Brasil. Segundo este decreto,

considera-se educação a distância a modalidade educacional na qual a mediação didático-pedagógica nos processos de ensino e aprendizagem ocorra com a utilização de meios e tecnologias de informação e comunicação, com pessoal qualificado, com políticas de acesso, com acompanhamento e avaliação compatíveis, entre outros, e desenvolva atividades educativas por estudantes e profissionais da educação que estejam em lugares e tempos diversos (BRASIL, 2017, art. $1^{\circ}$ ).

O curso de Bacharelado em Museologia da UNESPAR é o primeiro curso da área no Estado do Paraná e iniciou suas atividades no ano de 2019. Na sua Matriz Curricular e no Projeto Pedagógico do Curso ele é definido como "presencial", mas no momento em que foram estabelecidas as medidas de controle da pandemia do COVID- 19, o curso precisou se adaptar ao Ensino Remoto Emergencial. Tal modalidade foi autorizada pelo MEC e publicada no Diário Oficial da União no dia 18 de março de 2020, permitindo a substituição temporária das disciplinas presenciais nas universidades públicas pelo ERE, com o objetivo de amenizar os prejuízos causados pela pandemia.

Visando uma proposta exequível aos estudantes do segundo ano do curso de Museologia da UNESPAR, as professoras Ana Paula Peters, Luana Caroline Damião e Vivian Letícia Busnardo Marques estudaram a possibilidade de criação de um módulo transdisciplinar que teria como base três disciplinas da matriz curricular obrigatória do curso: "Museu, Patrimônio, História e Memória", "Documentação Museológica I" e “Administração Cultural e Marketing”.

\footnotetext{
${ }^{4} \mathrm{O}$ termo utilizado neste artigo não partiu do conceito de "Museu Imaginário” de André Malraux.
} 
O trabalho transdisciplinar quebra as barreiras entre as disciplinas e fomenta o trabalho conjunto e dialógico. Para Sousa e Pinho (2017), a transdisciplinaridade envolve três níveis de atuação: entre, através e além das disciplinas, assumindo um caráter multidimensional, que considera, além dos aspectos formais das áreas de conhecimento, os saberes e expressões tidos muitos vezes como não científicos, ou afetivos. Desse modo, para as autoras:

A transdisciplinaridade provoca o reordenamento de atitudes, promovendo uma abertura, um olhar sensível, catalisador das diferenças como via de ressignificação e construção permanente do cenário formativo. É o despertar de uma consciência que incide em uma (re)construção contínua da prática social caracterizadora de cada instituição, contribuindo para a reorganização do estabelecido e na criação de novas formas de atuação, tendo em vista o contexto mutável da sociedade em todas as suas dimensões (SOUSA; PINHO, 2017, p. 103)

Dentro dessa perspectiva, entendemos o cenário trazido pela pandemia como um contexto transformador dos fenômenos sociais e nas relações que alunos e professores estabelecem com o ambiente universitário, onde maneiras alternativas de se pensar e abordar as disciplinas ganham destaque. Assim, "é concebida uma construção compartilhada, cuja base de sustentação se dá no diálogo, na reciprocidade e na tentativa recorrente de constituição e reconstrução dos componentes envolvidos no ato formativo [...] em que professores e estudantes se informam e se transformam mutuamente" (SOUSA; PINHO, 2017, p. 104).

Buscando um teórico que contribuísse para um traçado metodológico neste momento pandêmico, nos apropriamos da teoria de Ausubel, no que diz respeito à aprendizagem significativa, entendida como:

um processo através do qual uma nova informação se relaciona de maneira não arbitrária e substantiva a um aspecto relevante da estrutura cognitiva do indivíduo. Neste processo a nova informação interage com uma estrutura de conhecimento específica, a qual Ausubel chama de "subsunçor", existente na estrutura cognitiva de quem aprende. $\mathrm{O}$ "subsunçor" é um conceito, uma idéia, uma proposição já existente na estrutura cognitiva, capaz de servir de "ancoradouro" a uma nova informação de modo que ela adquira, assim, significado para o indivíduo: a aprendizagem significativa ocorre quando a nova informação "ancora-se" em conceitos relevantes preexistentes na estrutura cognitiva (OSTERMANN; CAVALCANTI, 2010, p.34).

Ainda para Ausubel esta aprendizagem é um:

mecanismo humano para adquirir e reter a vasta quantidade de informações de um corpo de conhecimentos. Ausubel destaca o processo de aprendizagem significativa como o mais importante na aprendizagem escolar. A ideia mais importante da teoria de Ausubel e suas implicações para o ensino e a aprendizagem podem ser resumidas na seguinte proposição: 'se tivesse que reduzir toda a psicologia educacional a um só princípio, diria o seguinte: o fator isolado mais importante que influencia a aprendizagem é aquilo que o aprendiz já sabe' (MOREIRA; OSTERMANN, 1999, p. 45). Ausubel vê o armazenamento de informações na mente humana como sendo altamente organizado, formando uma espécie de hierarquia conceitual na qual elementos mais específicos de conhecimento são ligados a conceitos, ideias e proposições mais gerais e inclusivos.[...] [Já na aprendizagem mecânica] a nova informação é armazenada de maneira arbitrária e literal, não interagindo com aquela 
já existente na estrutura cognitiva e pouco ou nada contribuindo para sua elaboração e diferenciação (OSTERMANN; CAVALCANTI, 2011, p. 34-35).

Neste momento, buscando algo que já exista na estrutura cognitiva do aluno, no seu ambiente real, propôs-se que o estudante descobrisse em sua residência um objeto expressivo, com conexão afetiva, de memória, estética ou utilitária, cheio de significados para o estudo e o desenvolvimento da proposta do módulo "Do objeto real ao museu imaginário". Partindo ainda do pressuposto do objeto real a ser ressignificado para o módulo, verificou-se a necessidade da criação de um museu que deveria ser imaginado pelo aluno, o que permitiu a inserção deste objeto real dentro de uma narrativa institucional, justificando sua escolha e fazendo com que o aluno percorresse uma trajetória dentro das necessidades transdisciplinares.

\section{DO OBJETO REAL AO MUSEU IMAGINÁRIO}

Podemos entender que as disciplinas presentes no módulo exploram os seguintes pontos a partir de um olhar sobre o acervo: a história e a memória remetida ao objeto e a inserção no museu imaginário está presente em "História, Museu, Patrimônio e Memória"; a pesquisa faz parte das ações de "Documentação Museológica I"; e a comunicação e o desenvolvimento de projetos é trabalhada em "Administração Cultural e Marketing". A abordagem transdisciplinar traz ao aluno o aporte teórico e a aplicabilidade prática desse conhecimento em diversas etapas, simulando o ambiente real de atuação.

Os materiais relativos ao módulo foram postados em salas da ferramenta Google Classroom e os encontros síncronos foram realizados pelo Google Meet, ambos integrantes do programa GSuite, ambiente virtual de aprendizagem oferecido pela UNESPAR. As professoras trabalharam com textos, vídeos, áudios, slides, debates e encontros expositivos e dialógicos. A participação discente nos encontros semanais era acompanhada por meio de preenchimento de formulários do Google, através do uso de extensões e plugins que geram listas de participantes em tempo real e com a entrega de pequenos exercícios e atividades.

\subsection{HISTÓRIA, MUSEU, PATRIMÔNIO E MEMÓRIA}

A disciplina "História, Museu, Patrimônio e Memória" tem como ementa a introdução aos conhecimentos históricos a partir do estudo de fontes, discussões bibliográficas e das suas formas narrativas. Para isso, parte da História e historiografia do Paraná, estado onde se encontra este Bacharelado em Museologia, para apresentar e refletir sobre possíveis formas de abordar o conteúdo programático de forma didático-pedagógica em atividades voltadas à reflexão, a educação patrimonial e ações educativas em museus. Neste sentido, os conceitos de história, museu, memória e patrimônio se entrelaçam sobre questões contemporâneas que os atravessam como identidade, sociedade, memórias sociais e individuais, histórias escritas e orais e do patrimônio cultural. Temas como passados recontados, presente vividos e futuros possíveis, disputas contemporâneas pela memória, políticas patrimoniais e de rememoração ou esquecimento, subjetividades na construção do conhecimento a partir das diferentes dinâmicas das memórias frente aos desafios dos acontecimentos e transformações atuais das experiências sociais, históricas e culturais que vivenciamos trazem à tona a relação entre estes conceitos. Assim, conforme Delgado nos lembra, 
Tempo, memória, espaço e História caminham juntos. Inúmeras vezes, através de uma relação tensa de busca de apropriação e reconstrução da memória pela história. A relação tensionada acontece, por exemplo, quando se recompõem lembranças, ou se realizam pesquisas sobre guerras, vida cotidiana, movimentos étnicos, atividades culturais, conflitos ideológicos, embates políticos, lutas pelo poder. Sem qualquer poder de alteração do que passou, o tempo, entretanto, atua modificando ou reafirmando o significado do que foi vivido e a representação individual ou coletiva sobre o passado. Sem qualquer previsibilidade do que virá a ser, o tempo, todavia, projeta utopias e desenha com as cores do presente, tonalizadas pelas cores do passado, as possibilidades do futuro almejado (DELGADO, 2006, p. 34).

Estas questões foram divididas nos seguintes conteúdos: a construção do conhecimento histórico, através do estudo das fontes, das discussões bibliográficas e das formas narrativas; História e historiografia do Paraná e as formas de abordagens didático-pedagógicas a partir de exposições e publicações do Museu Paranaense, da Coleção Histórias do Paraná; história oral, narrativas, identidades e as dinâmicas da memória; Os museus e o patrimônio cultural como fonte histórica e de potencialidade na construção discursiva de narrativas históricas e como instrumento de ensino. Levando em consideração que o ponto de encontro entre as três disciplinas foi a escolha do objeto para a criação de um museu imaginário, o ponto essencial destes conteúdos para ser estudado no módulo voltou seu olhar às relações históricas e memórias que constituíam o objeto escolhido como também as narrativas encontradas a partir da investigação em fontes primárias ou de entrevistas com familiares e pessoas envolvidas com este objeto. Como ilustração da nossa proposta para os estudantes, comentamos sobre o Museu das Coisas Banais, instituição virtual que "tem o objetivo de promover uma reflexão em torno da memória agregada aos objetos cotidianos que, apesar de muitas vezes considerados banais, estabelecem uma relação afetiva ao longo do tempo e da vida com seus donos" . Afinal, nos dias atuais encontramos diferentes tipos de museus, "desde aqueles que abrigam as mais modernas inovações de nosso século e que recebem milhares de visitantes todos os dias, adaptados à sociedade de consumo em que se instalam, até outros bem pequenos, voltados basicamente para seu acervo original e comunidade mais próxima" (SANTOS, 2006, p. 16).

Perceber a dinâmica e transformação dos conceitos chaves que dão nome a esta disciplina foi um dos aspectos essenciais levados para a realização deste módulo. Ultimamente estamos passando pela redefinição do conceito de Museu pelo ICOM e o próprio conceito de patrimônio tem tido mais interesse com questões de identificação, preservação e divulgação. Dos monumentos de significado histórico reconhecidos pela História, alargam-se para sua ressignificação e aos centros históricos, ambientes, ecologias e paisagens. O patrimônio

não pode ser olhado apenas como reserva e, menos ainda, como recordação, mas como algo que faz parte do nosso presente. Por isso, só se poderá compreender o património e os problemas que coloca se se tiver em conta toda esta sua temporalidade intrínseca, que funciona como evidência para as questões que os historiadores queiram colocar (PINTO, 2011, 2016a). Também os museus, nesse caso, seriam lugares de ensino de história, onde a memória fosse tratada como fonte para o conhecimento e não como algo já conhecido (PINTO, 2019, p. 6).

Esta proposta também procurou levar os estudantes a refletirem sobre as transformações históricas que vem redefinindo os campos da memória e do patrimônio a partir da modernidade, bem como os

\footnotetext{
${ }^{5} \mathrm{https}: / /$ museudascoisasbanais.com.br/
} 
silenciamentos de algumas comunidades ou acontecimentos, por serem territórios de disputas e narrativas. Pois,

o direito à memória e à preservação do patrimônio cultural de distintos grupos constitui um exercício de cidadania importante para fundamentar as bases das transformações sociais necessárias para a coletividade. Além disso, o reconhecimento de identidades plurais, sejam elas de gênero, religião ou etnia, pressupõe a coexistência entre características culturais distintas que, em seu conjunto, contribuem para conformação de identidades mais genéricas, como, por exemplo, as identidades nacionais, feministas ou religiosas (PELEGRINI, 2007, p. 89).

A busca por objetos em casa proporcionou o reconhecimento da construção de narrativas individuais ou coletivas sobre o objeto, numa perspectiva de reconhecimento da diversidade e pluralidade de produção de memórias e conhecimento, reexaminando as narrativas existentes. Prática que os acompanhará no futuro exercício da profissão.

\subsection{DOCUMENTAÇÃO MUSEOLÓGICA}

Ao buscar debater o campo da atuação da Museologia, Chagas (1994) defende que as construções teóricas surgem a partir do senso comum e uma questão que pode emergir do imaginário coletivo é: por que os museus guardam objetos? Seja um objeto material ou um objeto conceito a guarda desses elementos acontece para preservar e difundir informações. Os objetos funcionam como testemunhos de fenômenos sociais que são levados aos museus para que possam, em conjunto com outros objetos, criar um circuito narrativo que conta uma história e reflete sobre determinados temas (o recorte temático e a missão de cada instituição). Além disso, "o acervo museológico é formado por objetos [...], de ampla variedade tipológica, podendo ser de cunho etnográfico, antropológico, arqueológico, artístico, histórico, tecnológico, imagético, sonoro, virtual, de ciências naturais, entre outros" (PADILHA, 2014, p. 21).

A cadeia operatória dos museus prevê para os objetos ações de preservação, de pesquisa e de comunicação. O objeto é entendido para a Museologia como um documento, e uma vez que é selecionado e retirado de seu contexto de uso corriqueiro na sociedade ele vai assumir novas funções na instituição, como representativo de facetas sociais. A documentação museológica faz parte dos processos de pesquisa e tem a função de justificar a presença desse objeto no museu. Para Ferrez (1991):

A documentação de acervos museológicos é o conjunto de informações sobre cada um dos seus itens e, por conseguinte, a representação destes por meio da palavra e da imagem (fotografia). Ao mesmo tempo, é um sistema de recuperação de informação capaz de transformar [...] as coleções dos museus de fontes de informações em fontes de pesquisa científica ou em instrumentos de transmissão de conhecimento (FERREZ, 1991, p.1).

Através da documentação, é possível explorar ao máximo as informações dos objetos e para esse processo são criadas fichas de registro que inventariam as informações de modo que elas possam ser transmitidas de forma mais eficiente nas ações de comunicação, como por exemplo as exposições, ações educativas, publicações, marketing institucional e pesquisas acadêmicas.

A disciplina "Documentação Museológica I" para o Bacharelado em Museologia prevê em seu conteúdo programático a exploração de diversos tópicos, dentre eles: o debate sobre o conceito de 
documento e informação; apresentação de sistemas de documentação museológica e a produção de fichas de registro; o uso de terminologia controlada; e as possibilidades de numeração e marcação dos objetos.

O cerne do módulo e ponto de debate para as três disciplinas foi o objeto e considerando que a documentação museológica deve se debruçar sobre a pesquisa e organização das informações do acervo, essa foi a proposta apresentada aos estudantes. Os discentes deveriam criar uma ficha de registro para inventariar o objeto. Essa ficha deveria ser baseada nos exemplos apresentados em aula, bem como em pesquisas feitas em sites de museus e instituições culturais. As fichas devem atender as necessidades do museu e a tipologia do acervo, ou seja, deve-se criar campos que digam das especificidades dos objetos, considerando que todas as informações presentes neste documento contribuirão para a preservação e comunicação do acervo. A partir disso, cada aluno apresentou uma proposta de ficha de registro e a preencheu segundo as informações de seu objeto, considerando as características do museu imaginário que faria sua tutela, uma vez que "cada objeto incorporado ao acervo é de compromisso do museu; por isso a forma pela qual é adquirido, analisado e difundido estabelecerá sua função social e cultural no ambiente do qual faz parte" (PADILHA, 2014, p. 27).

De acordo com o Comitê Internacional de Documentação (CIDOC/ICOM, 2014), as fichas de registro trabalham com grupos e categorias de informação, que são selecionadas ou criadas pelo museólogo documentalista considerando as características do acervo e da instituição. O CIDOC sugere vinte e dois grupos de informação, sendo eles: aquisição, estado de conservação, baixa patrimonial e alienação, descrição, imagem, instituição, localização, marca e inscrição, material e técnica, associação de objeto, coleta de objeto, registro de objeto, nome do objeto, número do objeto, produção do objeto, título do objeto, parte e componente, catalogação, referência, direitos de reprodução, assunto representado. Cada um desses grupos possui uma ou mais categorias de informação, que formam os campos da ficha de registro, por exemplo, o grupo "produção do objeto" tem as seguintes categorias sugeridas pelo CIDOC/ICOM (2014, p. 47): "local de produção, data de produção, nome do grupo/indivíduo produtor, função da produção".

$\mathrm{Na}$ confecção e preenchimento das fichas para o módulo, os alunos escolheram as categorias que melhor apresentariam as informações de seus objetos, de modo que mesmo a distância poderíamos entender as características do acervo apenas ao ler sua ficha e observar suas imagens. Nesse sentido, podemos compreender a documentação museológica como forma de comprovar e registrar as informações do objeto e os motivos que o fizeram ser preservado por uma instituição museal. Esse exercício prático coloca os alunos diante dos desafios que encontrarão na área enquanto museólogos, além de possibilitar um novo olhar aos objetos do cotidiano, tornando-os ainda mais significativos para a memória individual do estudante.

\subsection{ADMINISTRAÇÃO CULTURAL E MARKETING}

A disciplina Administração Cultural e Marketing, prevê na sua ementa a apresentação e a discussão da Política Nacional de Museus (PNM, 2003). O documento trata de uma mudança de postura pelo Ministério da Cultura, a fim de contemplar todos os museus brasileiros, independente da sua vinculação institucional: pública ou privada. Estas políticas públicas foram direcionadas aos bens culturais nacionais, estaduais e municipais, promovendo a valorização, a preservação, a difusão, o fomento e a fruição do patrimônio cultural brasileiro, considerado como um dos meios de cidadania e inclusão social, visando o desenvolvimento das instituições museológicas no Brasil. Em 2007, a PNM foi atualizada, trazendo as seguintes diretrizes norteadoras: 
1) Estabelecimento e consolidação de políticas públicas para os campos patrimônio cultural, da memória social e dos museus, visando à democratização das instituições e do acesso aos bens culturais. 2) Valorização do patrimônio cultural sob a guarda dos museus, compreendendo-os como unidades de valor estratégico nos diferentes processos identitários, sejam eles de caráter nacional, regional ou local. 3) Desenvolvimento de práticas e políticas educacionais orientadas para o respeito à diferença e à diversidade cultural do povo brasileiro. 4) Reconhecimento e garantia dos direitos das comunidades organizadas de participar, com técnicos e gestores culturais, dos processos de registro e proteção legal e dos procedimentos técnicos e políticos de definição do patrimônio a ser musealizado. 5) Estímulo e apoio à participação de museus comunitários, ecomuseus, museus locais, museus escolares e outros na Política Nacional de Museus e nas ações de preservação e gerenciamento do patrimônio cultural. 6) Incentivo a programas e ações que viabilizem a conservação, a preservação e a sustentabilidade do patrimônio cultural submetido a processo de musealização. 7) Respeito ao patrimônio cultural das comunidades indígenas e afrodescendentes, de acordo com as suas especificidades e diversidades (BRASIL, 2007, p.24-25).

Depois da publicação da PNM, foi criado o Sistema Brasileiro de Museus, por meio do Decreto ${ }^{\circ}$ 5.264, de 5 de novembro de 2004, este foi revogado pelo Decreto ${ }^{\circ}$ 8.124, de 17 de outubro de 2013, o qual regulamenta a criação do Instituto Brasileiro de Museus (IBRAM). Após a apresentação da Política Nacional de Museus e a criação do IBRAM, conteúdos norteadores da disciplina, iniciamos as discussões sobre a administração cultural, a apresentação dos organogramas de diversos museus, seu funcionamento e a importância de uma gestão interdisciplinar. Segundo Lewis (2015),

os museus cuidam da propriedade cultural do mundo e a traduzem ao público. Esta não é uma propriedade qualquer. Ela tem um prestígio especial na legislação e normalmente existem leis nacionais para protegê-la. Ela faz parte do patrimônio natural e cultural da humanidade e pode ser de caráter material ou imaterial. A propriedade cultural fornece frequentemente os indícios iniciais para uma série de disciplinas, como a arqueologia e as ciências naturais, e desta forma representa uma importante contribuição para o conhecimento. Ela também é um componente significativo para a definição da identidade cultural, nacional e internacionalmente (LEWIS, 2015, p.1).

A administração de museus e instituições culturais foram conteúdos tratados na disciplina, a importância do marketing cultural aplicado aos museus, a imagem do museu, a relação com o público visitante e a necessidade da construção de um plano de marketing:

O ponto de partida para uma estratégia de posicionamento, e consequente estratégia, deve ser análise e compreensão de como o museu se percepciona e é percepcionado em relação a outros museus e organizações que competem nas actividades de lazer, e isto exige, medir a imagem da organização (NUNES, 2010, p.16).

Sobre o cenário museal contemporâneo, Nunes (2010, p. 2), comenta: 'os 'museus do século XXI' necessitam actualmente de se apoiar no marketing a fim de rentabilizarem ao máximo as suas exposições, comunicando-as eficaz e eficientemente, de modo a espalhar a cultura [...] e criar hábitos culturais". 
As políticas de fomento também foram tratadas, a importância entre as parcerias entre Estado, iniciativa privada e terceiro setor (ONGs, OS, OSCIP, fundações), e as formas de captação de recursos.

Os museus estão cada vez mais conscientes que devem competir pelos seus públicos, pelos apoios e pelos recursos, que devem oferecer programas de qualidade, transmitir a sua singularidade, estabelecer relações a longo prazo com as comunidades locais e encontrar meios para se autofinanciarem, numa altura em cada vez mais se reduz o financiamento público (NUNES, 2010, p.2).

As leis de incentivo à cultura municipal, estadual e federal foram apresentadas e discutidas, bem como o exercício da elaboração de projetos culturais. Este último ponto ganhou destaque na metodologia do módulo transdisciplinar, já que os discentes elaboraram um projeto cultural específico para o objeto real selecionado (da sua residência) e seu museu imaginário (criado). Os estudantes deveriam propor um projeto cultural que fosse direcionado para a realização de pelo menos uma dentre as diversas possibilidades de ações, como por exemplo: ação educativa, expografia, impressão de livro, conservação e restauração, comunicação, evento cultural, entre outros. Desse modo, encontramos os princípios da teoria de Ausubel: "ensinar utilizando recursos e princípios que facilitem a assimilação da estrutura da matéria de ensino por parte do aluno e organização de suas próprias estruturas cognitivas nessa área de conhecimentos, através da aquisição de significados claros, estáveis e transferíveis" (OSTERMANN; CAVALCANTI, 2010, p. 35).

\section{CONSIDERAÇÕES FINAIS}

As professoras Ana Paula Peters, Luana Caroline Damião e Vivian Letícia Busnardo Marques, respectivamente das disciplinas "Museu, Patrimônio, História e Memória", "Documentação Museológica I" e "Administração Cultural e Marketing", realizaram um trabalho coletivo desde a elaboração do módulo "Do objeto real ao museu imaginário", suas diretrizes, planejamento até a sua execução, de modo remoto, devido à pandemia do COVID-19. Foram realizados encontros síncronos via Google Meet e materiais arquivados em sala específica do Google Classroom, os conteúdos das disciplinas foram tratados transdisciplinarmente e direcionados à avaliação final.

Após apresentação dos trabalhos finais dos discentes, concluímos que a metodologia utilizada foi positiva, a da escolha de um objeto real da residência do discente, o qual já tinha um significado para ele. O conhecimento que Ausubel chama de "subsunçor", está no cognitivo do discente, no objeto de pertencimento, de memória já existente, e este é capaz de servir como base para a construção do museu imaginário, adquirindo um novo significado para a execução da proposta do módulo.

Foram entregues como avaliação final do módulo um projeto transdisciplinar em único documento, contendo em ordem: explanações sobre o museu imaginário, como nome, missão, visão e valores da instituição fictícia; um texto sobre as relações de história, memória e patrimônio do objeto real; a documentação museológica do acervo, identificando-o na ficha de registro com a imagem do objeto e suas características; e o projeto cultural deste objeto, para fomento e marketing; todo o conjunto foi pautado no objeto real que deveria integrar o acervo do museu imaginário.

Dentre os trabalhos entregues podemos citar a criação do Museu do Dedal, constituído por uma uma coleção de doze dedais de diversos locais do mundo. A motivação para a escolha dos objetos foi afetiva, pois a avó da discente começou a coleção em uma viagem ao exterior e sua família manteve a tradição de trazer para ela esses dedais como souvenirs, que para além de uma função prática tem sua faceta estética e emotiva. Outro discente, apresentou como objeto real a vestimenta de fé 
denominada traje de Sama e criou o Museu Virtual de Indumentária, com o objetivo da transmissão cultural humana, da indumentária e dos hábitos de vestir como herança cultural. Alguns trabalhos tinham como ponto chave a proteção e divulgação da história e patrimônio paranaense, especificamente da cultura caiçara. Uma dessas propostas foi a do Museu Encantado, que visava trazer elementos dessa história de forma lúdica, através da divulgação de obras de arte que remetessem ao universo praiano incentivando a proteção ambiental. O objeto trazido pela discente foi a obra de arte Barcos do Futuro, de autoria de Elena Landinez e Mark Dayves.

Os resultados presentes nas avaliações entregues foram positivos, todos os vinte e dois alunos da turma participaram da atividade, entregando trabalhos individuais que foram apresentados na sala virtual para a troca de conhecimentos entre os discentes. Diante do desafio do ensino remoto e da proposta transdisciplinar, a qualidade dos trabalhos foi relevante, bem como a participação dos alunos no módulo. Utilizando os códigos e a aprendizagem significativa de Ausubel, as docentes buscaram incentivar os discentes, graduandos do Bacharelado em Museologia, mesmo em um momento pandêmico, a fim de trabalhar transdisciplinarmente um projeto que insere o real e o imaginário de cada um.

\section{REFERÊNCIAS}

AUSUBEL, D. P.; NOVAK, J. D.; HANESIAN, H. Psicologia Educacional. Rio de Janeiro: Editora Interamericana, 2. ${ }^{\mathrm{a}}$ edição, 1980.

BRASIL. Lei $\mathbf{n}^{\mathbf{0}}$ 8.313, de 23 de dezembro de 1991. Restabelece princípios da Lei $\mathrm{n}^{\circ}$ 7.505, de 2 de julho de 1986, institui o Programa Nacional de Apoio à Cultura (Pronac) e dá outras providências. Disponível em: http://www.planalto.gov.br/ccivil_03/leis/L8313compilada.htm. Acesso em: 29 abr. 2021.

BRASIL. Ministério da Cultura. Política Nacional de Museus. MINC. IPHAN, Brasília, 2007.

BRASIL. Decreto $\mathbf{n}^{0}$ 9.057, de 25 de maio de 2017. Regulamenta o art. 80 da Lei $\mathrm{n}^{\circ}$ 9.394, de 20 de dezembro de 1996 , que estabelece as diretrizes e bases da educação nacional. Disponível em: http://www.planalto.gov.br/ccivil_03/_Ato2015-2018/2017/Decreto/D9057.htm\#art24. Acesso em: 29 abr. 2021.

BRASIL. Ministério da Educação. Portaria $\mathbf{n}^{0}$ 343, de 17 de março de 2020. Dispõe sobre a substituição das aulas presenciais por aulas em meios digitais enquanto durar a situação de pandemia do Novo Coronavírus - COVID-19. Disponível em: https://www.in.gov.br/en/web/dou/-/portaria-n343-de-17-de-marco-de-2020-248564376. Acesso em 28 set. 2020.

CHAGAS, M. S. O Campo de Atuação da Museologia. In: Cadernos de Sociomuseologia, v.2, n. 2, 1994.

CIDOC/ICOM - Comitê Internacional de Documentação. Conselho Internacional de Museus. Declaração dos princípios de documentação em museus e Diretrizes internacionais de informação sobre objetos: categorias de informação do CIDOC. São Paulo: Secretaria de Estado da Cultura de São Paulo; Associação de Amigos do Museu do Café; Pinacoteca do Estado de São Paulo, 2014.

DELGADO, L. A. N. História oral: memória, tempo, identidades. Belo Horizonte: Autêntica, 2006. 
FERREZ, H. D. Documentação Museológica: teoria para uma boa prática. In: IV Fórum de Museus do Nordeste. Recife, 1991.

LEWIS, G. O Papel dos Museus e o Código de Ética Profissional. In: BOYLAN, P. J. (Coord.). Como gerir um museu: manual prático. Brodowski: Associação Cultural de Apoio ao Museu Casa de Portinari; São Paulo: Secretaria da Cultura do Estado de São Paulo, 2015.

NUNES, P. L. T.. Elaboração de um plano de marketing cultural para o Museu da Marinha. 2010. 120 f. Dissertação (Mestrado em Publicidade e Marketing) - Escola Superior de Comunicação Social, Instituto Politécnico de Lisboa, Lisboa, 2010. Disponível em: https://repositorio.ipl.pt/handle/10400.21/343. Acesso em 28 set. 2020.

OSTERMANN, F.; CAVAlCANTI, C. J. H. Teorias de Aprendizagem. Porto Alegre: Evangraf; UFRGS, 2011.

PADILHA, R. C. Documentação Museológica e Gestão de Acervo. Florianópolis: FCC, 2014.

PELEGRINI, S. C. A. O patrimônio cultural e a materialização das memórias individuais e coletivas.

Patrimônio e Memória. UNESP - FCLAs - CEDAP, v.3, n.1, 2007.

PINTO, H. Educação Patrimonial e Ensino de História: leituras do passado através do património cultural local. OPSIS (Online), Catalão-GO v. 19 (1), 2019, p. 1-21.

SANTOS, M. S. A escrita do passado em museus históricos. Rio de Janeiro: Garamond, MinC, IPHAN, DEMU, 2006.

SOUSA, J. G.; PINHO, M. J. Interdisciplinaridade e Transdisciplinaridade como fundamentos na ação pedagógica: aproximações teórico conceituais. Signos, Lajeado, ano 38, n. 2, p. 93-110, 2017. 